\title{
Quantitative trait loci associated with parasitic infection in Scottish blackface sheep
}

\author{
G Davies ${ }^{1,2}$, MJ Stear², M Benothman², O Abuagob², A Kerr², S Mitchell ${ }^{2}$ and SC Bishop ${ }^{1}$ \\ ${ }^{1}$ Roslin Institute (Edinburgh), Roslin, Midlothian EH25 9PS, UK; ${ }^{2}$ Department of Veterinary Clinical Studies, Glasgow University, \\ Bearsden Road, Glasgow G61 1QH, UK
}

\begin{abstract}
This study aimed to identify quantitative trait loci associated with endoparasitic infection in Scottish Blackface sheep. Data were collected from 789 animals over a 3-year period. All of the animals were continually exposed to a mixed nematode infection by grazing. Faecal samples were collected in August, September and October each year at ca. 16, 20 and 24 weeks of age; Nematodirus spp. eggs were counted separately from the other species of nematodes. Blood samples were collected in October from which immunoglobulin A ( $\lg A)$ activity was measured and DNA was extracted for genotyping. In total, 139 Microsatellite markers were genotyped across eight chromosomal regions (chromosomes 1, 2, 3, 5, 14, 18, 20 and 21) in the sires and progeny were genotyped for the markers that were poly-
\end{abstract}

morphic in their sire. Evidence was found for quantitative trait loci (QTL) on chromosomes 2, 3, 14 and 20. QTL associated with specific IgA activity were identified in chromosomes 3 and 20, in regions close to IFNG (chromosome 3 ) and the MHC (chromosome 20). QTL associated with Nematodirus FEC were identified on chromosomes 2, 3 and 14. Lastly, QTL associated with non-Nematodirus Strongyle FEC were identified on chromosomes 3 and 20. This study has shown that some aspects of host resistance to gastrointestinal parasites are under strong genetic control, therefore these QTL could be utilised in a marker-assisted selection scheme to increase host resistance to gastrointestinal parasites.

Heredity (2006) 96, 252-258. doi:10.1038/sj.hdy.6800788; published online 4 January 2006

Keywords: QTL; sheep; nematode; marker-assisted selection; faecal egg count; IgA

\section{Introduction}

Essentially all grazing sheep are exposed to parasitic nematodes. Gastrointestinal parasites cause a loss of production and subclinical infection can depress growth rate by at least one-third (Coop et al, 1985). Traditionally, parasitic nematodes were treated with anthelmintic compounds, however the development of anthelmintic resistance in nematode populations is fast becoming an international problem (Bartley et al, 2004). This has led to the need for new control measures.

Host resistance to parasites varies and much of this variation is under genetic control (Stear et al, 1997; Woolaston and Windon, 2001; Bishop and Stear, 2003; Quinnell, 2003). In the absence of new anthelmintic compounds or commercially available vaccines, an important first phase in finding a solution to the anthelmintic resistance problem has been the development of selective breeding schemes for parasite resistance in the UK, Australia and New Zealand. However, these schemes are based on selection for resistance using indicator traits, for example, faecal egg counts (FEC). Collecting and quantifying an indicator trait such as FEC is a costly and time-consuming process and also requires the animal to undergo parasitic challenge. Therefore, it would be very useful if it were possible to select directly for parasite resistance, for example by using quantitative trait loci (QTL) in a marker-assisted selection scheme.

Correspondence: G Davies, Roslin Institute (Edinburgh), Roslin, Midlothian EH25 9PS, UK. E-mail: Gail.Davies@bbsrc.ac.uk Received 18 August 2005; accepted 15 November 2005; published online 4 January 2006
Several studies have reported QTL associated with nematode resistance in sheep (Schwaiger et al, 1995; Coltman et al, 2001; Beh et al, 2002; Diez-Tascon et al, 2002; Janssen et al, 2002). These studies have utilised diverse approaches involving a variety of sheep breeds and nematode species; as a result little overall consensus has emerged. The objective of this current study was to identify QTL for a variety of indicators of nematode parasite resistance in sheep, and thus add to the available knowledge in this area. Indicators of host resistance were FEC for different nematode categories and immunoglobulin A (IgA) activity, as an indicator of host response. The host population comprised Scottish Blackface lambs.

\section{Materials and methods}

\section{Animals}

The study population comprised 789 Scottish Blackface lambs, comprising nine half-sib families ranging from 23 to 141 individuals. The animals were bred over a 3-year period (2001-2003) and sire and dam were recorded at birth for all animals. The complete pedigree for this population contained 4847 animals with records dating back to 1986.

The lambs were born outside and were continually exposed to natural mixed nematode infection by grazing. Lambs were kept in two groups each year with group representing the field grazed. Husbandry procedures followed standard commercial practice. Anthelmintic treatment was administered at the dosage rate recommended by the manufacturer every 28 days from 12 to 20 weeks of age. Treatment was by ivermectin (Oramec 
drench, Merial Animal Health) in 2001 and 2003 or levamisole (Nilverm, Schering-Plough Animal Health) in 2002.

\section{Phenotypic measurements}

Faecal samples were collected from the rectum of the lamb at 16, 20 and 24 weeks of age. FEC were made from a $3 \mathrm{~g}$ sample of faeces using the modified McMaster technique (Gordon and Whitlock, 1939; Bairden, 1991). Four replicates of each faecal sample were counted and each egg represented 12.5 eggs per gram of faeces. Eggs were classified according to whether they were Nematodirus spp. or other nematodes which in this study could include the following genera: Oesophagostomum, Chabertia, Bunostomum, Trichostrongylus, Cooperia, Ostertagia, Teladorsagia and Haemonchus. Collectively, these are referred to as 'Strongyles' in this paper. A previous study suggested that T. circumcincta is the predominant nematode species in this enviornment, accounting for three quarters of GI nematodes in Scottish sheep (Stear et al, 1998).

The activity of plasma IgA against a somatic extract of third-stage larvae from $T$. circumcincta was measured by indirect ELISA, as described by Strain et al (2002) on blood samples collected at 24 weeks of age. Relative IgA activity was measured as: (observed-standard)/(high control-standard), where the observed value is the sample mean from three replicates for the animal, the standard is the mean of three replicates from a pooled sample of helminth-naive lambs and the high control is the mean of three replicates from a pool of highresponder lambs (Sinski et al, 1995). The pool of highresponder lambs was created by combining equal quantities of plasma from six lambs that gave strong IgA responses following natural infection. The value for each animal wastherefore expressed as a proportion of a positive control.

\section{Genotyping and map construction}

All animals were genotyped using microsatellite markers across regions of varying length on chromosomes 1, 2, 3, $5,14,18,20$ and 21 . These eight chromosomes were chosen because previous studies suggested the existence of QTL for nematode resistance (chromosomes 3 and 21) or lamb performance traits such as growth rate or meat quality. Each region contained between 9 and 34 markers. All sires were genotyped for all markers across each region. Offspring were subsequently genotyped for markers that were heterozygous in their sire. In total 139 markers were genotyped. Relative marker locations were established by creating a linkage map for each chromosome using Cri-map (Green et al, 1990).

\section{Data analysis}

Data analysis began with an assessment of the distribution of the traits. All traits were transformed prior to further analysis; FEC measurements were log transformed, $\ln (\operatorname{trait}+x)$, where $x$ is a constant used to avoid zero values. Typically $x=$ half the measurement increment for the trait. IgA data were transformed using a cubed root transformation. These transformations successfully reduced the skewness of these traits, resulting in approximately normally distributed data.
For the QTL analysis the traits analysed were IgA, FEC at weeks 16, 20 and 24 for both Nematodirus and other species (ie 'Strongyles') as well as an average animal effect. A restricted maximum likelihood algorithm, ASREML (Gilmour et al, 1996), was fitted using a repeatability model (ignoring genetic effects) to create an average effect for each animal, that is the average weighted FEC across the three time points. Fixed effects fitted in this model were year, management group, sex, type (twin or single) and day of birth (fitted as continuous effect), and the calculations were performed on transformed FEC data.

Heritabilities were also estimated using ASREML. An animal model, including all known pedigree relationships (4847 animals), was fitted, with the same fixed effects as above. This analysis was repeated fitting a litter effect $\left(c^{2}\right)$; the significance of the litter effect was tested using a likelihood ratio test.

Estimation of QTL position: QTL analyses were performed using regression techniques (Knott et al, 1996) implemented by QTL express (Seaton et al, 2002). The probability of inheriting a particular sire chromosome at a particular position was calculated for each offspring at $1 \mathrm{cM}$ intervals. Phenotypes were then regressed upon the conditional probability that a particular haplotype is inherited from the sire, along each chromosome, fitting fixed effects of year, sex, litter size, management group and day of birth (fitted as a covariate). For each regression an F-ratio of the full model including the inheritance probability versus the same model without the inheritance probability was calculated across families; the location of the QTL was indicated by the largest F-value.

Significance thresholds: The 5\% chromosome-wide threshold was determined for each chromosome by permutation testing (1000 permutations) (Churchill and Doerge, 1994). A 5\% genome-wide threshold was then obtained by applying the Bonferroni correction (Knott et al, 1998): $P_{\text {genome-wide }}=1-\left(1-p_{\text {chromosome-wide }}\right)^{n}$, where $n$ is the number of chromosomes. The genome-wide threshold is based on the assumption that by chance you would expect 0.05 significant results per genome analysis.

Confidence intervals: For each QTL estimate that was significant at the 5\% chromosome-wide level confidence intervals were calculated using the bootstrap method (Visscher et al, 1996). In total, 1000 samples with replacement were used to estimate $95 \%$ confidence intervals.

Size of QTL effects: The proportion of phenotypic variance explained by the QTL was calculated as 4(1$\mathrm{MS}_{\text {full }} / \mathrm{MS}_{\text {reduced }}$ ), where MS is the residual mean square from the regression analysis (Knott et al, 1996). By dividing this phenotypic value by the heritability, estimated using ASREML, this results in the proportion of genetic variance explained by the QTL. As these results came from a half-sib analysis it was necessary to adjust the genetic proportion (GP) value to account for the proportional reduction in phenotypic variance expressed within sire families: Adjusted GP $=\mathrm{GP}\left(1-h^{2} / 4\right)$. 
The resulting value estimates the proportion of total additive genetic variance that is explained by the QTL.

\section{Results}

Summary statistics for the FEC traits and IgA are shown in Table 1. It is apparent from this data that the Nematodirus eggs are a small proportion of the total egg counts, as expected from previous results (Stear et al, 1998). Nematodirus FEC ranged from 0 to 1888 and other species (ie 'Strongyles') FEC ranged from 0 to 5325. FEC for both Nematodirus and other species were considerably larger in August than in either September or October. IgA activity against third-stage larvae ranged from 0 to 1.24 with a standard deviation of 0.19 .

Heritability estimates for all traits are shown in Table 2. The FEC heritability estimates are somewhat variable, being highest in August. IgA appears quite lowly heritable in this study population, although there was also a significant maternal effect.

Significant QTL are shown in Table 3. The QTL analysis suggested the existence of QTL on chromosomes 2, 3, 14 and 20, associated with both types of FEC and $\operatorname{IgA}$.

There were several QTL observed that were associated with Nematodirus FEC traits. A QTL associated with Nematodirus FEC September was observed on chromosome 2 (Table 3 ). The estimated position was $134 \mathrm{cM}$ and this QTL was significant at the 5\% genome-wide significance threshold. The QTL accounted for $52 \%$ of the total additive genetic variation (Table 4). A QTL associated with Nematodirus FEC August was found on chromosome 3 at $174 \mathrm{cM}$ (Figure 1). This was significant at both the 5\% chromosome-wide threshold and the 5\% genome wide threshold (Table 3), and it accounted for $26 \%$ of the additive genetic variation (Table 4 ).

There was evidence for QTL associated with Nematodirus FEC on chromosome 14. These QTL were associated with average animal effect, FEC August and FEC October at positions 103, 100 and $104 \mathrm{cM}$, respectively (Figure 2). This appears to be the same QTL effect that is being observed across these traits. All of the QTL observed on this chromosome were significant at the $5 \%$ genome-wide level. The QTL for average animal effect also reached significance at $1 \%$ chromosome-wide threshold. The QTL accounted for 79, 40 and 71\% of the additive genetic variance in average effect, August FEC and October FEC, respectively (Table 4). The QTL contour plots shown in Figure 2 illustrate the strength of the effects and the agreement across traits.

There was evidence for QTL associated with nonNematodirus spp. (ie 'Strongyles') FEC traits on chromosomes 3 and 20. A QTL associated with the October FEC was found at $150 \mathrm{cM}$ on chromosome 3 (Figure 1). The QTL accounted for $37 \%$ of the additive genetic variance for the average animal effect (Table 4). On chromosome 20 a QTL was observed at $10 \mathrm{cM}$ (Figure 3) associated with average animal effect. This QTL was in the region of the MHC and accounted for nearly one-third (31\%) of the total additive genetic variance.

On chromosomes 3 and 20 QTL associated with IgA activity were also found. The QTL on chromosome 3 was at position $118 \mathrm{cM}$ (Figure 1) and was significant at the $5 \%$ genome-wide threshold (Table 3 ). The QTL explained $41 \%$ of the additive genetic variation (Table 4 ). On chromosome 20 indications of a QTL were observed for IgA activity at $40 \mathrm{cM}$ (Figure 3). This QTL was significant at the 5\% chromosome-wide threshold (Table 3) and the QTL accounted for slightly over half (51\%, Table 4$)$ of the total additive genetic variation in IgA activity. This QTL is also in the region of the MHC.

\section{Discussion}

This study has identified QTL on four chromosomes for various FEC traits and IgA activity. The QTL identified on two of these chromosomes are close to regions that influence immune function.

Table 2 Heritabilities

\begin{tabular}{|c|c|c|c|c|}
\hline Trait & $h^{2}$ & s.e. & $c^{2}$ & s.e. \\
\hline Nematodirus FEC August & 0.30 & 0.11 & & \\
\hline Nematodirus FEC September & 0.21 & 0.09 & & \\
\hline Nematodirus FEC October & 0.19 & 0.09 & & \\
\hline Nematodirus average animal effect ${ }^{\mathrm{a}}$ & 0.24 & 0.09 & & \\
\hline Strongyles ${ }^{b}$ FEC August & 0.50 & 0.12 & & \\
\hline Strongyles FEC September & 0.11 & 0.07 & & \\
\hline Strongyles FEC October & 0.21 & 0.09 & & \\
\hline Strongyles average animal effect ${ }^{\mathrm{a}}$ & 0.23 & 0.09 & & \\
\hline IgA activity & 0.18 & 0.09 & 0.13 & 0.06 \\
\hline
\end{tabular}

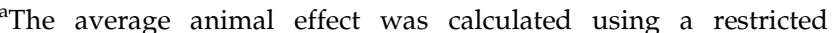
maximum likelihood algorithm, ASREML (Gilmour et al, 1996), fitting a repeatability model to calculate the average weighted FEC across the three time points.

${ }^{\mathrm{b}}$ Strongyles refers to all species present other than Nematodirus.

Table 1 Summary statistics

\begin{tabular}{|c|c|c|c|c|c|c|c|}
\hline Trait & $\begin{array}{c}\text { Age } \\
\text { (weeks) }\end{array}$ & $\begin{array}{c}\text { No. of } \\
\text { observations }\end{array}$ & Mean & $\operatorname{Max}^{\mathrm{a}}$ & $\begin{array}{c}\text { Mean of } \\
\text { transformed data }\end{array}$ & $\begin{array}{l}\text { Standard deviation } \\
\text { of transformed data }\end{array}$ & $\begin{array}{c}\text { Skewness of } \\
\text { transformed data }\end{array}$ \\
\hline IgA activity & 24 & 757 & 0.13 & 1.24 & 0.42 & 0.21 & 0.37 \\
\hline Nematodirus FEC $^{b}$ August & 16 & 740 & 39.0 & 1888 & 3.62 & 0.74 & 2.5 \\
\hline Nematodirus FEC ${ }^{b}$ September & 20 & 722 & 22.2 & 675 & 3.61 & 0.60 & 1.5 \\
\hline Nematodirus FEC $^{\mathrm{b}}$ October & 24 & 741 & 30.3 & 600 & 3.67 & 0.71 & 1.4 \\
\hline Strongyles ${ }^{\mathrm{c}}$ FEC $^{\mathrm{b}}$ August & 16 & 740 & 256 & 5325 & 4.85 & 1.28 & 0.21 \\
\hline Strongyles $\mathrm{FEC}^{\mathrm{b}}$ September & 20 & 721 & 288 & 2550 & 5.19 & 1.12 & -0.15 \\
\hline Strongyles FEC ${ }^{\mathrm{b}}$ October & 24 & 741 & 236 & 1700 & 5.12 & 1.02 & -0.30 \\
\hline
\end{tabular}

${ }^{\mathrm{a}}$ The minimum value for each trait was zero.

${ }^{\mathrm{b}}$ FEC units: eggs per gram of faeces (epg).

'Strongyles refers to all species present other than Nematodirus. 
Table 3 QTL significant at 5\% chromosome-wide significance level

\begin{tabular}{|c|c|c|c|c|c|c|c|}
\hline Trait & Chromosome & $\begin{array}{l}\text { Position } \\
(c M)\end{array}$ & Marker region & $F$ & $\begin{array}{l}5 \% \text { Chromosome- } \\
\text { wide threshold }\end{array}$ & $\begin{array}{l}5 \% \text { Genome-wide } \\
\text { threshold }\end{array}$ & $\begin{array}{c}95 \% \text { confidence } \\
\text { interval }\end{array}$ \\
\hline Nematodirus FEC September & 2 & 134 & ВM81124-СР79 & 3.06 & 2.88 & 2.96 & $44-203$ \\
\hline IgA activity & 3 & 118 & KD103-LYZ & 2.48 & 2.48 & 2.96 & $36-189.5$ \\
\hline Nematodirus FEC August & 3 & 174 & BM6433-BMS772 & 3.43 & 3.41 & 2.96 & $0-202.5$ \\
\hline Strongyles FEC October & 3 & 150 & CSRD111-TEXAN15 & 2.59 & 2.44 & 2.96 & $0-205$ \\
\hline Nematodirus average animal effect & 14 & 103 & ILSTS002-LSCV30 & 5.26 & 2.42 & 2.96 & $65-123$ \\
\hline Nematodirus FEC August & 14 & 100 & BMS833-ILSTSO02 & 3.54 & 3.17 & 2.96 & $0-151$ \\
\hline Nematodirus FEC October & 14 & 104 & ILSTS002-LSCV30 & 3.74 & 2.61 & 2.96 & $32-146.5$ \\
\hline Strongyles ${ }^{\mathrm{a}}$ average animal effect & 20 & 10 & DYA-MCMA36 & 2.64 & 2.44 & 2.96 & $0-59$ \\
\hline IgA activity & 20 & 40 & BM1815-DRB1 & 2.90 & 2.45 & 2.96 & $1-65$ \\
\hline
\end{tabular}

${ }^{\text {a }}$ Strongyles refers to all species present other than Nematodirus.

Table 4 Proportions of variation attributable to QTL effect

\begin{tabular}{lccc}
\hline Trait & Chromosome & Heritability & Phenotypic proportion \\
\hline Nematodirus FEC September & 2 & 0.21 & 0.12 \\
IgA activity & 3 & 0.18 & 0.08 \\
Nematodirus FEC August & 3 & 0.30 & 0.08 \\
Strongyles FEC October & 3 & 0.21 & 0.08 \\
Nematodirus average animal effect & 14 & 0.24 & 0.20 \\
Nematodirus FEC August & 14 & 0.30 & 0.13 \\
Nematodirus FEC October & 14 & 0.19 & 0.14 \\
Strongyles average animal effect & 20 & 0.23 & 0.37 \\
IgA activity & 20 & 0.18 & 0.79 \\
\hline
\end{tabular}

${ }^{\text {a }}$ Strongyles refers to all species present other than Nematodirus.

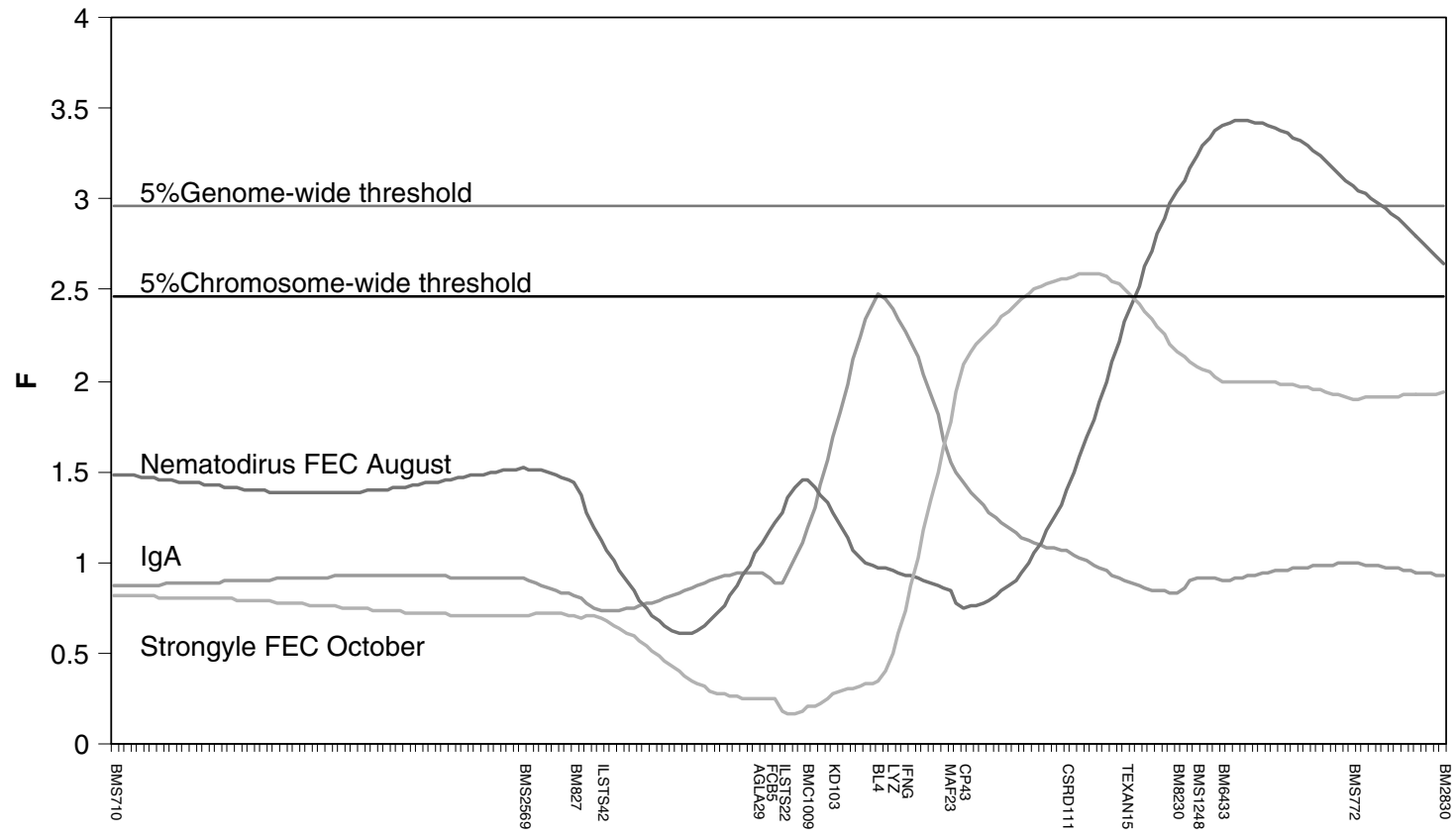

Figure 1 QTL contour plot chromosome 3.

The QTL on chromosome 3 associated with IgA activity is very close to the interferon gamma locus (IFNG). IFN- $\gamma$ has an important role in the regulation of the immune response to pathogens (Urban et al, 1996; Wakelin 1996). IFN- $\gamma$ is a cytokine that is secreted by Th1 lymphocytes. It activates macrophages, which then become more capable of killing intracellular pathogens and display increased ability to present antigens. Previous evidence for QTL associated with parasitic infection on chromosome 3 in the region of IFNG has 


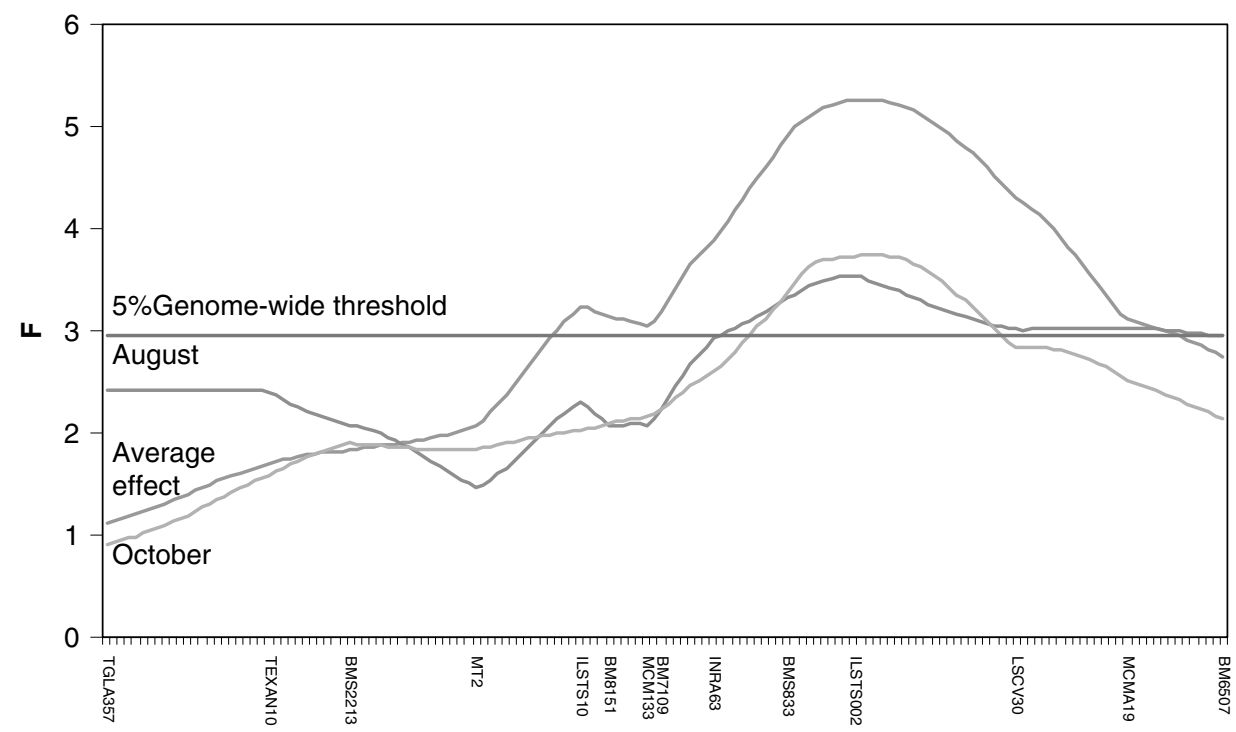

Figure 2 QTL contour plot chromosome 14; Nematodirus FEC traits.

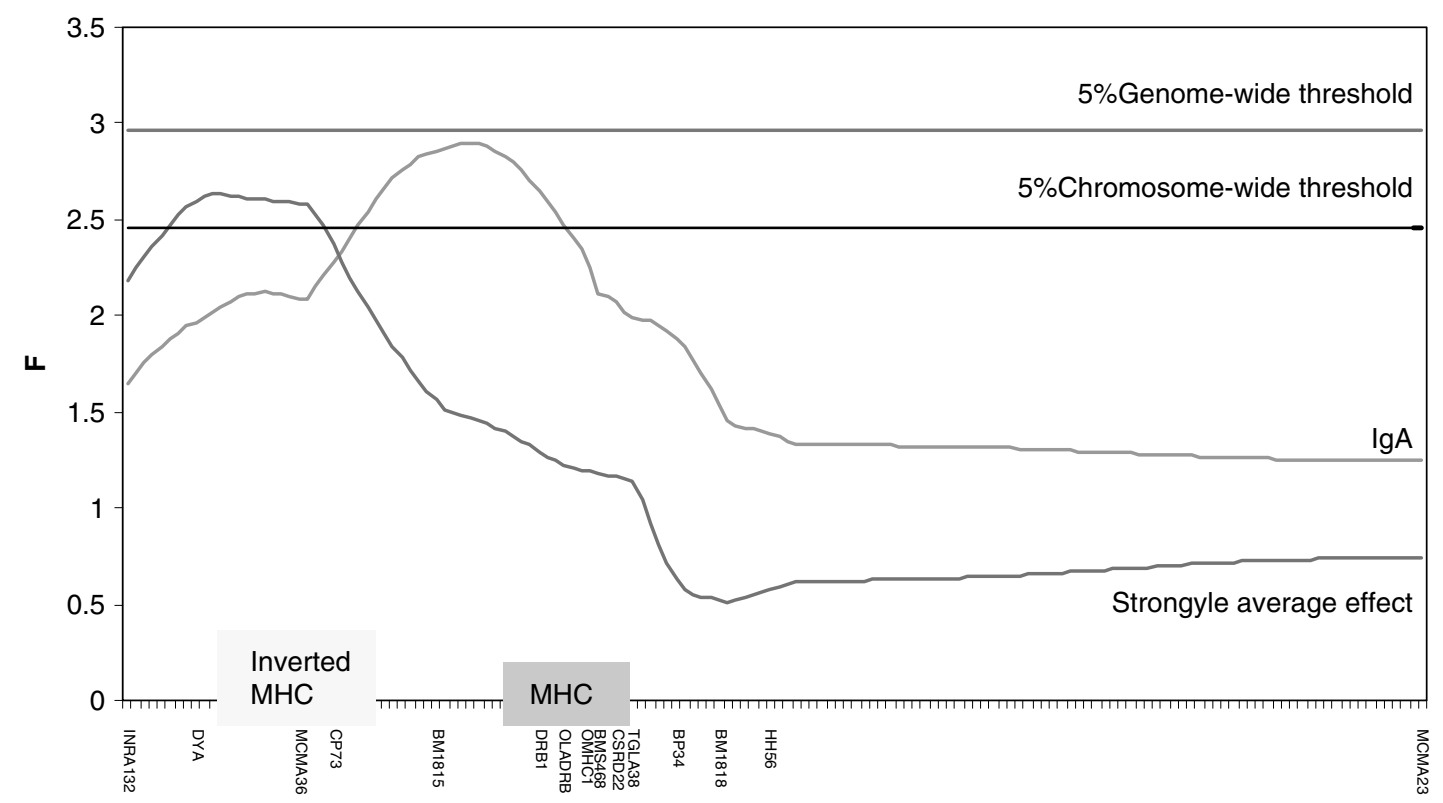

Figure 3 QTL contour plot chromosome 20.

been reported in several studies. Paterson et al (1999) suggested a QTL in the interval IFNG - BMS1617 for a multispecies parasite challenge in Romney divergent selection lines. Evidence for a QTL associated with $T$. circumcincta was reported in Soay sheep again close to IFNG (Coltman et al, 2001) and a QTL for T. colubriformis was observed in Merino divergent selection lines in the IFNG region (Beh et al, 2002). Although these QTL are very close to the QTL identified in this study they are in diverse breeds, challenged with different species of nematodes.

In sheep the Major Histocompatibility Complex (MHC) is found in two regions of chromosome 20. The QTL found on chromosome 20 in this study are both very close to the $\mathrm{MHC}$ regions. These regions are likely to contain possible candidate genes as the MHC consists of a group of closely linked genes involved in antigen presentation to the vertebrate immune system. The primary immunological function of MHC molecules is to bind and 'present' antigenic peptides on the surfaces of cells for recognition by the antigen-specific T-cell receptors of lymphocytes. Several studies including Buitkamp et al (1996), Outteridge et al (1996), Paterson et al (1998) and Charon et al (2002) have implicated both regions of the MHC as QTL for nematode resistance. Schwaiger et al (1995) reported a QTL close to DRB1 in Scottish Blackface sheep facing a $T$. circumcincta natural challenge. Secondly, three marker associations within the $\mathrm{MHC}$ region were reported in a Roehnschaf flock for haematocrit level (CP73), IgL level (DYMS1) and FEC 
(BM1815) after an artificial challenge with Haemonchus contortus (Janssen et al, 2002). This again is evidence within a similar chromosomal region, despite the fact that the Roehnschaf study involves artificial challenge with a different parasite and different trait measurements.

The QTL effects calculated in this study appear very large for some of the traits when expressed as a proportion of the genetic variance, however, due to low heritability estimates for some traits the QTL effects expressed in relation to the total phenotypic variance are more modest. Additionally, we found the Nematodirus FEC heritability estimates to be very sensitive to the data transformation used, specifically to the increment added to the raw value to avoid zeroes. Therefore, the estimate of the proportion of genetic variability may be less precise than the estimate of the phenotypic variance explained. However, when we estimated the effect of the transformation on QTL locations and significance values, we found the results to be robust and insensitive to different transformations, that is the QTL positions were essentially identical irrespective of the transformation used, and the F-ratios were only slightly affected. It is important to note that the Nematodirus FEC data are skewed by an abundance of 0 values, and even after transformation it is not normally distributed. This affects variance component estimates but not the QTL results. Aspects affecting the interpretation of data skewed by zero scores are discussed by Dominik (2005), with the suggestion that nonparametric tests could be used in such situations. However, even with data having an abundance of zero values the application of parametric tests, following appropriate mathematical transformation of the raw data, is generally superior to the use of nonparametric tests (Tilquin et al, 2001).

In conclusion this study has provided strong evidence for QTL linked to parasitic infection and immune response on chromosomes 2, 3, 14 and 20. The QTL on chromosomes 2 and 14 affect egg production by Nematodirus spp., and more work is necessary to confirm these associations and identify potential candidate genes. Chromosomes 3 and 20 have been previously associated with nematode resistance and contain candidate genes that influence immune function. Unfortunately, there is only a small amount of previously published work relating to QTL for parasite resistance and within those studies there is little common ground regarding breed, parasite challenge and traits measured. The chromosome exhibiting the strongest evidence for a QTL in this study does not have any candidates obvious to us and this requires further work to identify the genes underlying this region. The result of this study suggest that some aspects of parasite resistance are under strong genetic control and with further work this information could be used to select sheep for increased resistance to parasitic infection in a marker-assisted selection scheme.

\section{Acknowledgements}

This work was funded by the European Community under Framework 5 (QLK5-CT-2000-00656) and the flock was maintained by funding from Defra. We wish to thank Dougie McGavin and David Wallace at Blythbank farm for their assistance. $\mathrm{M}$ Benothman and $\mathrm{O}$ Abuagob were sponsored by the Faculty of Veterinary Medicine, Al-Fatah University, Libyan Educational Authority.

\section{References}

Bairden K (1991). Ruminant Parasitic Gastroenteritis: Some Observations on Epidemiology and Control. PhD Thesis, University of Glasgow.

Bartley DJ, Jackson F, Jackson E, Sargison N (2004). Characterization of two triple resistant field isolates of Teladorsagia from Scottish lowland sheep farms. Vet Parasitol 123: 189-199.

Beh KJ, Hulme DJ, Callaghan MJ, Leish Z, Lenane I, Windon RG et al (2002). A genome scan for quantitative trait loci affecting resistance to Trichostrongylus colubriformis in sheep. Anim Genet 33: 97-106.

Bishop SC, Stear MJ (2003). Modeling of host genetics and resistance to infectious diseases: understanding and controlling nematode infections. Vet Parasitol 115: 147-166.

Buitkamp J, Stear MJ, Epplen JT (1996). Class I and class II major histocompatability complex alleles are associated with faecal egg counts following natural, predominantly Ostertagia circumcincta infection. Parasitol Res 82: 693-696.

Charon KM, Moskwa B, Rutkowski R, Gruszczynska J, Swiderek W (2002). Microsatellite polymorphism in DRB1 gene (MHC Class II) and its relation to nematode faecal egg count in Polish Heath Sheep. J Anim Feed Sci 11: 47-58.

Churchill GA, Doerge RW (1994). Empirical threshold values for quantitative trait mapping. Genetics 138: 963-971.

Coltman DW, Wilson K, Pilkington JG, Stear MJ, Pemberton JM (2001). A microsatellite polymorphism in the gamma interferon gene is associated with resistance to gastrointestinal nematodes in a naturally-parasitized population of Soay sheep. Parasitology 122: 571-582.

Coop RL, Graham RB, Jackson F, Wright SE, Angus KW (1985). Effect of experimental Ostertagia circumcincta infection on the performance of grazing lambs. Res Vet Sci 38: 282-287.

Diez-Tascon C, Macdonald PA, Dodds KG, McEwan JC, Crawford AM (2002). A screen of chromosome 1 for QTL affecting nematode resistance in an ovine outcross population. Proceedings 7th World Congress on Genetics Applied to Livestock Production. Communication No. 13-37.

Dominik S (2005). Quantitative trait loci for internal nematode resistance in sheep: a review. Genet Select Evol 37: S83-S96.

Gilmour AR, Thompson R, Cullis BR, Welham S (1996). ASREML. Biometrics Bulletin 3 NSW Agriculture.

Gordon HM, Whitlock HV (1939). A new technique for counting nematode eggs in sheep faeces. I Council Sci Ind Res Australia 12: 50.

Green P, Falls K, Crooks S (1990). Cri-map Version 2.4. [2.4]. Washington University School of Medicine: St. Louis, MO.

Janssen M, Weimann C, Gauly M, Erhardt G (2002). Associations between infections with haemonchus contortus and genetic markers on ovine chromosome 20. Proceedings 7th World Congress on Genetics Applied to Livestock Production. Communication No. 13-11.

Knott SA, Elsen J-M, Haley CS (1996). Methods for multiplemarker mapping of quantitative trait loci in half-sib populations. Theoret Appl Genet 93: 71-80.

Knott SA, Marklund L, Haley CS, Andersson K, Davies W, Ellegren $\mathrm{H}$ et al (1998). Multiple marker mapping of quantitative trait loci in a cross between outbred wild boar and large white pigs. Genetics 149: 1069-1080.

Outteridge PM, Anderson L, Douch PGC, Green RS, Gwakisa PS, Hohenhaus MA et al (1996). The PCR typing of MHCDRB genes in the sheep using primers for an intronic microsatellite: application to nematode parasite resistance. Immunol Cell Biol 74: 330-336.

Paterson KA, McEwan JC, Dodds KG, Morris CA, Crawford AM (1999). Fine mapping a locus affecting host resistance to internal parasites in sheep. Proc Assoc Adv Anim Breed Genet 13: 91-94 
Paterson S, Wilson K, Pemberton JM (1998). Major histocompatability complex variation associated with juvenile survival ad parasite resistance in a large ungulate population (Ovis aries L.). Proc Natl Acad Sci 95: 3714-3719.

Quinnell RJ (2003). Genetics of susceptibility to human helminth infection. Int I Parasitol 33: 1219-1231.

Schwaiger FW, Gostomski D, Stear MJ, Duncan JL, McKellar QA, Epplen JT et al (1995). An ovine Major Histocompatibilty Complex DRB1 allele is associated with low faecal egg counts following natural, predominantly Ostertagia circumcincta infection. Int J Parasitol 25: 815-822.

Seaton G, Haley CS, Knott SA, Kearsey M, Visscher PM (2002). QTL Express: mapping quantitative trait loci in simple and complex pedigrees. Bioinformatics 18: 339-340.

Sinski E, Bairden K, Duncan JL, Eisler MC, Holmes $\mathrm{PH}$ McKellar QA et al (1995). Local and plasma antibodyresponses to the parasitic larval stages of the abomasal nematode Ostertagia circumcincta. Vet Parasitol 59: 107-118.

Stear MJ, Bairden K, Bishop SC, Gettinby G, McKellar QA, Park $\mathrm{M}$ et al (1998). The processes influencing the distribution of parasitic nematodes among naturally infected lambs. Parasitology 117: 165-171.
Stear MJ, Bairden K, Duncan JL, Holmes PH, McKellar QA, Park M et al (1997). How hosts control worms. Nature 389: 27.

Strain S, Bishop SC, Henderson NG, Holmes PH, McKellar QA, Mitchell S et al (2002). The genetic control of IgA activity and its association with parasite resistance in naturally infected sheep. Parasitology 124: 545-552.

Tilquin P, Coppieters W, Elsen JM, Lantier F, Moreno C, Baret PV (2001). Statistical power of QTL mapping methods applied to bacteria counts. Genet Res 78: 303-316.

Urban JF, Fayer R, Sullivan C, Goldhill J, Shea-Donohue T, Madden $\mathrm{K}$ et al (1996). Local TH1 and TH2 responses to parasitic infection in the intestine: regulation by IFN-gamma and IL-4. Vet Immunol Immunopathol 54: 337-344.

Visscher PM, Thompson R, Haley CS (1996). Confidence intervals in QTL mapping by bootstrapping. Genetics 143: 1013-1020.

Wakelin D (1996). Immunity to Parasites; How Parasitic Infections Are Controlled. Cambridge University Press: Cambridge.

Woolaston RR, Windon RG (2001). Selection of sheep for response to Trichostrongylus colubriformis larvae: genetic parameters. Anim Sci 73: 41-48. 